\title{
Quantitative Variable
}

National Cancer Institute

\section{Source}

National Cancer Institute. Quantitative Variable. NCI Thesaurus. Code C142658.

A variable that can be expressed with numeric values. 